\title{
Emoções docentes em relação ao processo de inclusão escolar ${ }^{1}$
}

\section{Teachers' emotions in relation to the school inclusion process}

\author{
Paula Maria Ferreira de Faria* \\ Denise de Camargo*
}

\begin{abstract}
RESUMO
$\mathrm{O}$ artigo apresenta uma pesquisa cujo principal objetivo foi compreender as emoções do professor em relação ao processo de educação inclusiva e ao aluno em inclusão a partir dos referenciais da Teoria Histórico-Cultural de Vigotski. O estudo, de caráter qualitativo, foi realizado com três professoras dos anos iniciais do Ensino Fundamental de uma escola municipal da periferia do Município de Curitiba. A análise dos dados foi norteada pelos princípios da Análise de Conteúdo de Bardin (1977) e envolveu o uso de entrevistas estruturadas, semiestruturadas e a produção de registros fotográficos. Os dados foram categorizados segundo as vivências das participantes como alunas, como docentes e em relação à inclusão de alunos com necessidades educacionais especiais na classe regular. Os resultados apontam, apesar da presença de emoções agradáveis, como alegria e satisfação, o predomínio de emoções desagradáveis relacionadas à docência inclusiva, como insegurança, frustração e pena. O estudo indica a maior valorização dos aspectos cognitivos, minimizando a importância da emoção no processo de inclusão escolar. A pesquisa revela que as emoções têm sido desvalorizadas inclusive pelas próprias docentes que, ao desconhecê-las, privam-se da possibilidade de utilizá-las como promotoras de crescimento pessoal e transformação do trabalho docente.
\end{abstract}

Palavras-chave: Emoções. Professores. Inclusão escolar. Teoria HistóricoCultural. Vigotski.

$1 \mathrm{O}$ desenvolvimento da pesquisa contou com o financiamento da Agência da Coordenação de Aperfeiçoamento de Pessoal de Nível Superior (CAPES) - bolsa de Mestrado.

*Universidade Federal do Paraná. Curitiba, Paraná, Brasil. E-mail: paula.pmff@gmail. com - https://orcid.org/0000-0001-6804-8711 E-mail: denicamargo@gmail.com - https://orcid. org/0000-0001-9092-9988 


\begin{abstract}
The article presents a research whose main objective was to understand the teacher's emotions in relation to the process of inclusive education and to the student in inclusion from the references of the Cultural-Historical Theory of Vygotsky. The study, qualitative in nature, was carried out with three teachers of the initial years of Elementary School from a municipal school on the outskirts of the Municipality of Curitiba. The analysis of the data was guided by the principles of Bardin's Content Analysis (1977) and involved the use of structured and semi-structured interviews and the production of photographic records. The data were categorized according to the experiences of the participants as students, as teachers and in relation to the inclusion of students with special educational needs in the regular classrooms. The results point out, despite the presence of pleasant emotions such as joy and satisfaction, the predominance of unpleasant emotions related to inclusive teaching, such as insecurity, frustration and regret. The study indicates a greater appreciation of cognitive aspects, minimizing the importance of emotion in the process of school inclusion. The research reveals that the emotions have been devalued even by the teachers themselves who, unaware of them, deprive themselves of the possibility of using them as promoters of personal growth and transformation of teaching work.
\end{abstract}

Keywords: Emotions. Teachers. School inclusion. Historical-Cultural Theory. Vygotsky.

\title{
Sentindo as emoções: contextualizando a pesquisa
}

O processo de inclusão escolar refere-se ao acolhimento do educando com necessidades educacionais especiais nas classes regulares, propiciando apoio adequado tendo em vistas o desenvolvimento pleno de seu potencial. A ideia da educação inclusiva considera que as escolas "deveriam acomodar todas as crianças independentemente de suas condições físicas, intelectuais, sociais, emocionais, linguísticas ou outras" (UNESCO, 1994). A efetivação desse processo envolve diretamente a atuação docente, como apontam as Diretrizes Curriculares Nacionais para a Educação Básica:

A educação básica deve ser inclusiva, no sentido de atender a uma política de integração dos alunos com necessidades educacionais especiais nas 
classes comuns dos sistemas de ensino. Isso exige que a formação dos professores das diferentes etapas da educação básica inclua conhecimentos relativos à educação desses alunos (BRASIL, 2001, p. 26).

Embora seja premente a necessidade de investimento na formação docente e do desenvolvimento de práticas de formação continuada para que o professor possa atuar de forma efetivamente inclusiva, esse não é o único aspecto necessário para a implementação da educação inclusiva; de fato, a efetivação do processo de inclusão escolar demanda o enfrentamento e a superação de vários desafios.

De forma geral, a formação docente para a atuação em classes inclusivas não abrange a preparação emocional para a nova atividade. Destaca-se o preparo cognitivo voltado ao conhecimento teórico das especificidades das necessidades educacionais especiais e para a aprendizagem de estratégias didático-pedagógicas, mas as emoções de professores e alunos em relação a esse processo são ignoradas (FARIA; CAMARGO, 2018). Ao privilegiar a cognição em detrimento da emoção, a formação de professores reflete o padrão cartesiano tradicional do sistema educacional, que marginaliza e ignora a emoção. Assim,

[...] prevalece ainda a velha e enganosa concepção de que emoção e razão são funções independentes e excludentes. Não constitui, portanto, nenhuma surpresa, a constatação de que, para muitos professores, as emoções e os sentimentos ainda são vistos como perturbadores da aprendizagem, e portanto, devem ser controlados, sufocados ou ignorados (CAMARGO, 2004, p. 27).

A separação entre aspectos afetivos e cognitivos tem sido denunciada há décadas. No contexto escolar, a cisão entre intelecto e afeto ignora a interdependência dinâmica entre os processos intelectuais e afetivos, negando a importância do estímulo afetivo sobre o desenvolvimento infantil (VIGOTSKI, 1997).

Segundo Vigotski (1997, 2004), pensamento e emoção representam partes do todo indivisível que é a consciência humana; configura-se, assim, um padrão dinâmico e constante de relações entre os aspectos cognitivos e afetivos, que conduzem ao desenvolvimento.

Vigotski (2004) enfatiza a importância dos aspectos afetivos na escola: 
A emoção não é um agente menor do que o pensamento. O trabalho do pedagogo deve consistir não só em fazer com que os alunos pensem e assimilem geografia, mas também a sintam. Por algum motivo essa ideia não costuma vir à cabeça, e o ensino de colorido emocional é entre nós um hóspede raro [...] (VIGOTSKI, 2004, p. 144).

Enfatiza-se, portanto, a relevância dos fatores emocionais no processo de ensino-aprendizagem. Nesse contexto, a atuação docente precisa considerar os elementos mobilizadores de emoção, pois são os maiores propulsores da aprendizagem. Dessa forma, a escola não pode se preocupar exclusivamente com o desenvolvimento cognitivo: "o aspecto emocional do indivíduo não tem menos importância do que outros aspectos e é objeto de preocupação da educação nas mesmas proporções em que o são a inteligência e a vontade" (VIGOTSKI, 2004, p. 146).

De acordo com a Teoria Histórico-Cultural proposta por Vigotski (1997, 2004, 2011), as expressões e reações emocionais são fundamentais à efetivação da aprendizagem. Nesse sentido, a atuação docente não se pauta somente por procedimentos, técnicas e conteúdos: todo o processo de ensino-aprendizagem é permeado pelas vivências e experiências, pelas emoções tanto dos alunos como também do professor. A forma como se desenvolvem as relações afetivas entre professor e alunos, portanto, é um dos fatores que determinam o sucesso dessa interação e, consequentemente, a aprendizagem.

A realidade da educação inclusiva adiciona novos elementos à relação professor-aluno. Para além dos fatores emocionais presentes na classe regular, somam-se as expectativas dos docentes frente ao desafio da inclusão; assim, conscientemente ou não, as emoções do professor são mobilizadas, influenciando sua forma de agir e se relacionar com todos os alunos. Nesse processo dialético contínuo, à medida que trabalha com os aspectos emocionais implicados no processo de inclusão escolar, o professor se depara também com as próprias emoções.

Vigotski $(1997,2004,2011)$ também voltou seus interesses ao desenvolvimento e educação de crianças com deficiências - a "defectologia", como era chamada na época. Vislumbrando além das limitações orgânicas da criança com deficiência, o autor apontava também os entraves ao desenvolvimento cultural desses alunos. Assim, mais importante que a própria deficiência é a qualidade das mediações estabelecidas, pois a forma e a qualidade das interações pode gerar êxito ou fracasso no processo de desenvolvimento. Em outras palavras, para o autor, é preciso lembrar que, para além das dificuldades, o foco não está na incapacidade, mas na pessoa em desenvolvimento (VIGOTSKI, 1997, 2011). 
Ao adotar uma postura positiva diante da deficiência, Vigotski $(1997,2011)$ opõe-se à ênfase sobre o que a criança não é e o que não pode fazer. Nesse sentido, aponta que a escola deve utilizar estratégias de ensino diferenciadas, nunca se deixando limitar ou aceitando passivamente as dificuldades apresentadas pelo aluno. Essa nova compreensão do aluno modifica inteiramente a prática docente em sala de aula:

Que perspectivas se abrem ao pedagogo quando sabe que a deficiência não é apenas uma falta, uma limitação, uma fraqueza, mas também uma vantagem, uma fonte de força e de aptidões, que nela há um certo sentido positivo! (VIGOTSKI, 1997, p. 46, tradução nossa)

Vigotski $(1997,2011)$ preconiza, portanto, uma postura ativa e positiva por parte da escola, defendendo o potencial de todo e qualquer aluno, a ser desenvolvido através de um processo de ensino adequado, que inclua a interação e a cooperação em atividades coletivas. Tal processo só é possível, no entanto, a partir da integração entre os elementos emocionais e cognitivos, considerando a necessidade e a influência de ambos os processos para o pleno desenvolvimento humano.

Assim como Vigotski (2004, p. 69), acreditamos que "cada minuto do homem está cheio de possibilidades não realizadas"; compreendemos, portanto, a importância das emoções em todos os contextos de ação humana, em especial no ambiente escolar. Nesse sentido, apontamos que as emoções têm sido relegadas na atividade docente, inviabilizando a realização de múltiplas possibilidades em sala de aula.

Considerando a necessidade de valorizar, para além dos aspectos cognitivos, a forma como o professor se sente diante da inclusão, e respaldados pelos referenciais de Vigotski (1997, 2004), desenvolvemos a pesquisa relatada neste artigo. O objetivo geral do estudo foi compreender as emoções do professor em relação ao processo de educação inclusiva e ao aluno da inclusão. Como objetivos específicos, a pesquisa pretendeu, ainda: caracterizar o perfil pessoal, acadêmico e profissional dos participantes da pesquisa; identificar as emoções do professor em relação ao seu percurso escolar, acadêmico e profissional; compreender de que forma as emoções do professor influenciam o processo de inclusão escolar; e analisar as relações entre as emoções do professor em sua trajetória de aluno a docente e suas emoções em relação à inclusão escolar. Buscamos, com o desenvolvimento da pesquisa, apontar as emoções do professor enquanto expressões autenticamente humanas, por meio das quais é possível concretizar novas e diferentes possibilidades em sala de aula. 


\section{Sistematizando as emoções: percurso metodológico da pesquisa}

A compreensão da subjetividade sob a perspectiva da Teoria HistóricoCultural demanda procedimentos metodológicos que envolvem uma postura dialógica e a valorização das características singulares em seu contexto próprio de significados e sentidos. Torna-se fundamental, especialmente no estudo das emoções, considerar a especificidade desses aspectos que não podem ser objetivados por meio de quantificação direta ou mera racionalização, mas constituem formações e processos subjetivos essenciais para a configuração da identidade (GONZÁLEZ REY, 2013).

Por considerar a singularidade social de cada sujeito em seu contexto histórico e cultural, acreditamos que a pesquisa qualitativa se adéqua aos pressupostos da Teoria Histórico-Cultural proposta por Vigotski $(1997,2004)$, que reconhece a subjetividade enquanto produção humana que só pode ser significada a partir das experiências pessoais do sujeito, marcadas pelas condições de sua cultura em determinado contexto histórico. Dessa forma, considerando nossos princípios teóricos e epistemológicos, optamos pela utilização da abordagem qualitativa, tendo em vista que esse tipo de pesquisa propicia melhores condições de estudar e compreender nosso fenômeno de interesse, permitindo-nos uma maior aproximação da complexidade do tema.

Visando atingir os objetivos da pesquisa, os instrumentos de pesquisa foram classificados em três campos de investigação. Cada campo investigativo abordou um aspecto da pesquisa, definido pelos objetivos específicos a ele relacionados: o primeiro abrangeu o delineamento dos participantes da pesquisa; o segundo campo voltou-se às emoções das participantes da pesquisa em seu histórico escolar, desde a trajetória como alunas até a atuação docente; o terceiro campo investigativo abordou o processo de autofotografia como instrumento de expressão emocional diante do processo de inclusão escolar e ao aluno de inclusão.

O estudo foi realizado em uma escola da Rede Municipal de Ensino de Curitiba $^{2}$, com três professoras dos anos iniciais do Ensino Fundamental (identificadas aqui como professoras Violeta, Rosa e Margarida). A pesquisa foi estruturada em dois encontros individuais com cada professora, com duração aproximada de cinquenta minutos cada. Foram utilizadas entrevistas estruturadas, semiestruturadas e também a produção de fotografias pelas participantes.

2 A pesquisa relatada neste artigo foi submetida ao Comitê de Ética em Saúde da Universidade Federal do Paraná - CAAE nº 83997818.6.0000.0102. 
Na pesquisa qualitativa, a fotografia é compreendida a partir dos elementos que a contextualizam; trata-se de um processo centrado no sujeito que permite acessar aspectos subjetivos por meio da interpretação relatada pelo próprio fotógrafo (NEILVA-SILVA; KOLLER, 2002). Ressaltamos o caráter sociocultural e histórico que envolve o ato fotográfico, pois "toda fotografia é marcada pelo olhar de quem a produziu e a sua leitura traz as marcas dos olhares de quem a admira, ambos olhares socialmente constituídos" (MATTOS; ZANELLA; NUERNBERG, 2014, p. 902). Assim, a leitura das imagens fotográficas é permeada pelos sentidos que cada pessoa atribui, singularmente, conforme suas experiências de vida e de cultura, em um determinado momento. Em nossa pesquisa, buscamos compreender quais os sentidos atribuídos pelas professoras aos registros fotográficos e como expressam suas emoções diante da inclusão escolar através de suas fotografias.

Para analisar os conteúdos objetivados por meio das fotografias, optamos pela utilização da Análise de Conteúdo de Bardin (1977), que pode ser definida como

[...] um conjunto de técnicas de análise das comunicações visando obter, por procedimentos sistemáticos e objetivos de descrição do conteúdo das mensagens, indicadores (quantitativos ou não) que permitam a inferência de conhecimentos relativos às condições de produção/recepção (variáveis inferidas) destas mensagens (BARDIN, 1977, p. 42).

No primeiro encontro, realizamos uma entrevista estruturada para delinear o perfil pessoal, acadêmico e profissional das participantes, e também uma entrevista semiestruturada, visando ampliar a compreensão dos dados coletados por meio do instrumento estruturado e também conhecer as emoções das professoras em suas trajetórias, desde alunas até o exercício da docência. Ainda neste encontro, apresentamos a consigna da autofotografia às professoras: "registre, em cinco fotografias, suas emoções em relação ao processo de inclusão escolar e ao(s) seu(s) aluno(s) em inclusão". As participantes foram orientadas a fazer o registro fotográfico a partir de seus próprios telefones celulares e enviar as imagens para a pesquisadora dentro de um período de trinta dias. As professoras foram informadas de que as fotografias poderiam ser produzidas em qualquer ambiente e utilizando-se de qualquer tipo de cena ou objeto que atendesse à consigna inicial.

No segundo encontro, realizado no período de trinta dias após o primeiro contato, cada participante recebeu as fotografias que havia produzido e enviado 
à pesquisadora; a partir delas, foi realizada uma entrevista semiestruturada, explorando os significados e sentidos expressos em relação aos alunos de inclusão e ao processo inclusivo.

Todas as entrevistas foram realizadas nas dependências da escola em que lecionavam as participantes, durante o primeiro semestre do ano de 2018.

\section{Significando as emoções: análise e discussão dos dados}

Compreendemos que os processos de análise e interpretação dos dados estão inter-relacionados na pesquisa qualitativa, e só por meio da integração de ambos os processos é possível compreender os dados produzidos na pesquisa de forma ampla e contextual (GIL, 2008). Por isso, a análise dos dados envolve também a reflexão sobre eles e sua interpretação, respaldados pelo viés teórico da Teoria Histórico-Cultural.

As professoras Margarida, Rosa e Violeta são casadas e residem com os maridos, e a maioria (66,7\%) não tem filhos; a média de idade é de 36,3 anos. Todas se formaram em instituições particulares, sendo uma na modalidade de educação a distância. Duas professoras são formadas em Pedagogia, e uma, em Letras, e duas professoras cursaram o Magistério no Ensino Médio. Todas as professoras possuem ao menos uma especialização. Em relação às áreas de especialização, duas professoras têm pós-graduação em Psicopedagogia.

A busca pela complementação da formação através de cursos de especialização indica a busca por fundamentos teóricos que subsidiem a atuação docente, apontando a valorização de elementos cognitivos que referenciem a prática no contexto escolar.

As três participantes são professoras efetivas do Sistema Municipal de Ensino e lecionam em ambos os períodos (manhã e tarde), perfazendo uma carga horária de trabalho de 40 horas semanais. O tempo médio de atuação docente das professoras é de 13,3 anos. O exercício do magistério em tempo integral por longos períodos de tempo pode indicar a sobrecarga profissional, cuja repercussão física e emocional pode afetar a atividade docente (CRUZ et al., 2010; REIS et al., 2006).

Margarida, Rosa e Violeta atuam como regentes de turmas inclusivas do primeiro ciclo de aprendizagem, com uma média de 28 alunos por sala. Embora somente Rosa possua experiência na área da Educação Especial, as três professoras relataram experiências anteriores com alunos de inclusão. Violeta 
e Margarida relataram ter parentes próximos com deficiências adquiridas, porém nenhuma das participantes da pesquisa declarou ter necessidades educacionais especiais.

Todas as professoras relataram vivências positivas relacionadas ao contexto escolar, vinculadas tanto ao ambiente da escola como ao processo de ensino-aprendizagem.

Eu me sentia bem na escola / Para mim foi excelente, né (Margarida).

Quando eu entrei na primeira série, era aquela emoção, aquela vontade assim, tudo. / Me sentia mais confiante para continuar, para não desistir (Rosa).

Só coisas boas, assim, coisas alegres. / É, foi uma boa experiência (Violeta).

Rosa e Violeta apontam o desejo de infância de ser professora.

Desde criança, eu sempre gostei de brincar de escolinha / Eu era a única que brincava de escolinha / E eu contei que eu queria ser professora / E na minha segunda série... eu contei para minha professora que eu queria ser professora (Rosa).

Começa lá desde pequena, na verdade, né, que a gente brinca de escolinha / Desde cedo comecei a dar catequese... na verdade isso já vem alimentando essa ideia de ser professora (Violeta).

De fato, o professor é uma das primeiras profissões com as quais as crianças têm contato constante; dessa forma, a familiaridade com os modos de ser e atuar do professor contribui para a construção do desejo de infância de ser professora (ARROYO, 2017). Evidencia-se, portanto, que vivências das participantes em suas trajetórias de alunas influenciam suas formas de se relacionar com a escola e com a própria profissão.

As participantes relatem a influência - positiva ou negativa - da família sobre a escolha da profissão: 
Meu pai sempre falava "menina mulher tem que fazer magistério", aquela história, né? [risos] (Margarida).

[Meu pai disse:] "Que professora, filha? Você é tão aplicada, tão inteligente... por que professora?!" / [Ele falou:] "Filha, mas você vai ser pobre para o resto da vida" (Rosa).

A despeito da influência familiar, no entanto, consideramos que, para além das preferências e decisões individuais de cada professora, a opção pela docência é uma produção sociocultural (ARROYO, 2017). O professor carrega uma imagem ideal, socialmente construída, de sua profissão, com a qual convive antes mesmo de ingressar no ambiente escolar. Nesse sentido, o desejo de ser professora parece estar relacionado às visões idealizadas das famílias de origem acerca do que é ser professor. Além disso, a opção pela docência, para as professoras Violeta, Rosa e Margarida, parece indicar uma suposta predestinação vinculada ao gênero: ser mulher implica em ser mãe, cuidar, educar, ser professora. A imagem social da professora, construída historicamente ao longo dos anos, mescla as características de professora e mãe, enfatizando os atributos "maternos" da docência em detrimento de suas especificidades profissionais. Apontamos que essa imagem feminina não é neutra, mas relacionase intimamente "a determinados modos sociais de viver a condição de mulher" (ARROYO, 2017, p. 128). Frisamos, contudo, que para a Teoria HistóricoCultural, a ideia de vocação "se opõe à visão da construção histórica do sujeito, colocando-o como obra da natureza"; ao adotar tal concepção, "anulamos do homem a condição de sujeito ativo e criamos uma ilusão que provoca a sujeição social" (AGUIAR, 2006, p. 13). É preciso, portanto, considerar a posição ativa de cada indivíduo sobre o processo de escolha de sua profissão. Dessa forma, a partir da compreensão de que o homem se constitui na e pelas relações sociais que estabelece em seu contexto cultural e histórico, consideramos que a opção pela carreira do Magistério também desvela essa mesma realidade, evidenciando a subjetividade social de cada professora (AGUIAR, 2006).

Um fator presente no discurso das três professoras relacionado à dificuldade no exercício da docência inclusiva envolve a falta de formação específica para a atuação nesses contextos. 
Não tem essa formação (Margarida).

Porque eu não sou formada e eu não tenho nenhuma pós, ou nenhuma especialização, enfim, nada na questão da inclusão, né, que possa me auxiliar / Deveria partir de mim, de repente, uma formação? Não sei, mas todos os professores deveriam então estar formados na Educação Especial para atender as crianças? [risos] (Violeta).

Essa questão tem sido apontada pela literatura como uma das principais barreiras à efetivação da inclusão na escola (SAMPAIO, C.; SAMPAIO, S., 2009). Nesse sentido, a formação docente ultrapassa o mero treinamento ou capacitação, indicando "um acompanhamento contínuo ao professor no cotidiano de sua prática"; assim, a questão da formação aponta também para o "registro da subjetividade, sinalizando para o aspecto existencial da formação do indivíduo" (SAMPAIO, C.; SAMPAIO, S., 2009, p. 54).

É importante destacar que o discurso das professoras aponta a necessidade de formação exclusivamente cognitiva, direcionada ao conhecimento das características das necessidades educacionais especiais e de estratégias didáticopedagógicas que facilitem a realização da inclusão em sala de aula - a questão do preparo emocional não é mencionada pelas professoras. Essa postura coaduna-se com o modelo tradicional de formação de professores, que ignora a necessidade de uma formação mais abrangente e aberta. Para superar essa visão, julgamos necessário considerar todos os aspectos que requerem "preparo" do professor, o que necessariamente inclui, para além da capacitação cognitiva, também o desenvolvimento de estratégias socioemocionais. Ou seja,

[...] enquanto as professoras falam de um despreparo de ordem pedagógica, salientamos que também está em jogo um despreparo psíquico para lidar com a realidade, às vezes tão difícil de aceitar, que a deficiência traz, [...] como também, no caso da prática docente, apontar os limites de uma prática pedagógica voltada, prioritariamente, para as aquisições cognitivas (SAMPAIO, C.; SAMPAIO, S., 2009, p. 149).

Outro aspecto destacado pelas três participantes da pesquisa é a necessidade de apoio ao professor para o trabalho inclusivo. 
A gente aceita, porém a gente sabe que falta alguma coisa / Então nós, assim, não... é, não temos assim, muito com quem conversar / Na verdade a gente tem o que nós buscamos. Basicamente é isso / O apoio é sempre para a criança (Violeta).

Então nós precisamos ter também todo esse suporte. Porque podem até cobrar da gente na escola, mas e lá? / Mas eu preciso também ter esse outro suporte (Rosa).

É o que eu não tive nos outros anos. Porque eu não tinha nenhuma professora que viesse para dar um apoio (Margarida).

A troca de saberes e experiências com outros professores em redes de apoio e aprendizagem gera um ambiente colaborativo, no qual o professor pode expressar suas dúvidas e angústias, receber apoio e também colaborar para com o desenvolvimento de outros professores. Assim, ao se expressar e trocar experiências dentro de um grupo com outros profissionais, o professor pode estabelecer novos referenciais e desenvolver novas formas de compreender e atuar sob a perspectiva inclusiva.

Ao longo das entrevistas, as professoras Rosa, Violeta e Margarida relataram suas vivências enquanto alunas e professoras, revelando suas relações com a instituição escolar e com os alunos, bem como suas concepções sobre a inclusão escolar e sobre seus alunos de inclusão. No decorrer de todo esse processo, emergiram diferentes emoções. $\mathrm{O}$ discurso das três professoras indica que as emoções agradáveis vivenciadas como alunas influenciaram a relação positiva estabelecida com o contexto escolar; evidenciando que "os sentimentos e emoções presentes na sala de aula marcam de maneira significativa a relação dos alunos com o conhecimento, produzindo movimentos de aproximação ou afastamento" (TASSONI; LEITE, 2011, p. 90).

Embora incitadas a relatar suas emoções a partir de suas produções fotográficas, nem sempre as professoras eram capazes de nomear o que sentiam - não raramente, apresentavam dificuldade em nomear suas emoções. O relato da professora Margarida ilustra essa questão, revelando a dificuldade da professora até mesmo em utilizar o termo "emoção":

Ah, é até dificil assim explicar [pausa]. Mas eu acho que eu falo mais dele [do aluno] do que da minha [emoção], não consigo mostrar [minha emoção], é igual eu falei para você, eu não sei nem explicar o que que eu sinto... dele... não sei se eu consegui te passar isso... (Margarida). 
Além disso, todas as professoras reportaram durante as entrevistas vivências emocionais atribuídas aos alunos de inclusão - relatando o que eles sentiam (na percepção das professoras), em vez de suas próprias emoções.

Ela não se sente diferente neste momento, ela se sente participante como os demais (Violeta).

Veja que raramente ele expressa alguma [emoção]... o rostinho dele. Ele tem, sim, expressão de sorriso, ele faz, né? Mas às vezes ele não [expressa nenhuma emoção]... (Margarida).

A dificuldade das participantes em expressar as próprias emoções faz com que as professoras busquem nomear as vivências emocionais de seus alunos. O processo de direcionar-se ao outro parece indicar uma tentativa de proteção emocional das professoras, diante do que não se quer - ou não se pode - exprimir.

Em todas as fotografias de Margarida, Rosa e Violeta, o elemento central da imagem apontava a realização de atividades pedagógicas pelos alunos de inclusão. $\mathrm{O}$ estabelecimento desse foco indica a intenção de demonstrar a realidade prática e concreta da inclusão dos alunos em sala de aula, enfatizando indiretamente a ação docente por meio da realização de diversas atividades de cunho pedagógico. Adicionalmente, os discursos das professoras dirigiam-se mais a aspectos cognitivos na efetivação da inclusão (como a necessidade de formação específica e a adaptação das atividades dos alunos) - apesar da ênfase dada às emoções no processo de entrevista. Em todos esses aspectos, nota-se a clara dificuldade das professoras em abordar a temática das emoções - e, em especial, para expressá-las.

De fato, falar sobre (e mesmo refletir acerca das) próprias emoções tem sido um processo negligenciado em nossa sociedade. Tal dificuldade reverbera o modelo cartesiano, que dicotomiza intelecto e afeto, privilegiando a cognição e desvalorizando as emoções (CAMARGO, 2004). A dificuldade em abordar as próprias emoções reflete ainda um processo de desconhecimento da própria subjetividade, que acaba por dificultar o processo de ação consciente e livre, limitando as possibilidades de ação (e transformação) da docência inclusiva.

Compreendemos que as emoções reveladas a partir das análises fotográficas desvelam os sentidos atribuídos às práticas de inclusão escolar pelas participantes da pesquisa.

O discurso de Rosa (a única dentre as professoras que possui formação na área da Educação Especial) reitera suas emoções agradáveis em relação à docência. 
A escolha pela Educação Especial foi minha / Eu falo que, no caso é... é [escolha] de vida, mesmo / Toda a minha linha de interesse sempre foi em relação a isso / O que eu escolhi como formação para minha vida, trabalhar com Educação Especial.

Eu amo. Eu amo o que eu faço.

Esse é o meu meio, aqui que eu me sinto feliz. Aqui, a escola, que é a minha alegria.

As vivências emocionais de Rosa indicam o desenvolvimento de vínculos positivos com a profissão; assim, compreendendo as emoções como condição e produto do contexto cultural e histórico, contribuindo para a construção de um sentido pessoal de identificação com a docência. Em consonância com as emoções agradáveis relacionadas à opção pelo magistério, Rosa expressa segurança quanto à efetivação da inclusão em sala de aula, apontado emoções relacionadas à leveza e satisfação com o trabalho.

Então pra mim não é um fardo, não é? (Rosa).

Mas para mim não é algo que vai me estressar, vai me cansar; muito pelo contrário (Rosa).

Alinhada à sua concepção de inclusão escolar - e seu declarado interesse pela área da Educação Especial, a professora Rosa expressa emoções agradáveis relacionadas ao trabalho que desenvolve. O discurso de Rosa evidencia as emoções relacionadas à empatia e à identificação com o outro, expressando o desejo de contribuir com seu aluno com necessidades educacionais especiais.

Hoje, quando eu vejo ele [aluno de inclusão], assim, todo esse desenvolvimento que a gente está buscando com ele, eu me sinto ótima, realizada, é muito bom (Rosa).

Inversamente, o discurso de Margarida enfatiza a vivência de emoções desagradáveis quanto à inclusão escolar: 
Você sai frustrada. É uma frustração e uma... uma sensação, assim, de impotência (Margarida).

Margarida aponta a impotência e a frustração - emoção que revela a lacuna entre o desejado e o possível, expondo os limites da atuação da professora e indicando uma forma particular de sofrimento relacionada à prática docente (SOUZA; PETRONI; ANDRADA, 2013). A professora enfatiza não as emoções de seu aluno, mas justamente a ausência de expressões emocionais - e, em um processo análogo, também ela revela dificuldades em expressar suas emoções. O discurso de Margarida revela a contradição entre suas emoções - entre o que realmente sente e o que se permite sentir.

Não vou falar que é dó, não vou falar isso, porque a gente, acho que não é um sentimento bom pra gente ter de uma pessoa, né? Mas eu fico assim, ao mesmo tempo, preocupada (Margarida).

É igual eu falei, né, é dó. A gente fica, vocêfica toda hora, "nossa, que dó" né? (Margarida).

Esse conflito ressalta que a expressão emocional revela conceitos, valores, crenças e ideologias, expondo aspectos dos quais nem sempre estamos conscientes ou que, intencionalmente, preferimos ocultar - como forma, inclusive, de evitar situações de sofrimento.

Entre os relatos de Rosa e Margarida, a professora Violeta se posiciona de forma mais neutra em relação à inclusão - enfatizando, no entanto, desconfiança em relação a esse processo.

Eu não tenho muita preocupação e nem frustração com relação a isso. [...] Claro, você sempre tem um pé atrás (Violeta).

Embora Violeta atribua vivências emocionais agradáveis ao aluno de inclusão, tais como suas próprias experiências enquanto aluna, seu discurso revela emoções antagônicas em relação ao magistério, relacionadas ao ambiente escolar, expressando incertezas e dificuldades em relação à docência inclusiva. 
Que bom que ela consegue fazer, mas que pena que ela não tem outros atendimentos que deveria ter (Violeta).

Ah, isso dá uma frustração. A gente se frustra sim (Violeta).

Surpresa? Não... tem alguma coisa além, assim ... angústia, aflição? Sabe, o que eu vou fazer para atendê-los bem, da forma como eles necessitam e precisam? Então dá assim, uma insegurança (Violeta).

As emoções relatadas pelas professoras revelam distintas formas de vivenciar a realidade da profissão em uma mesma escola, reforçando que os sentidos atribuídos pelas professoras à inclusão revelam formas individualmente sociais de sentir e compreender a realidade. As vivências e emoções de Margarida, Rosa e Violeta revelam, portanto, formas próprias de apreender e sentir a docência, constituídas a partir de suas vivências pessoais, familiares e profissionais. Dessa forma, compreendemos que

[...] conhecer as emoções do professor frente à inclusão é conhecer a realidade da educação inclusiva por dentro, por detrás dos discursos treinados e estereotipados. A emoção é expressão impactante e autêntica e revela como o professor verdadeiramente se relaciona com a inclusão (FARIA; CAMARGO, 2018, p. 224).

\section{Ressignificando as emoções: considerações sobre a pesquisa}

De acordo com os princípios da Teoria Histórico-Cultural, compreendemos que as emoções das professoras objetivam formas de apreensão da realidade material e concreta vivenciada diariamente em sala de aula. Consideramos fundamental, portanto, compreender os relatos das professoras como objetivações concretas de uma realidade subjetiva situadas em um contexto cultural e histórico: aliada à desvalorização da imagem social do professor, objetivada nos baixos salários e na desgastante jornada de trabalho, há ainda a sobrecarga (física e emocional) advinda da responsabilidade de promover a aprendizagem de alunos com necessidades diferenciadas de aprendizagem. A formação de professores, que deveria contribuir para a concretização da 
nova demanda, permanece frágil e compartimentalizada, alheia às reais necessidades do professor. Nesse contexto, preparado ou não, cabe ao professor (produto de um sistema excludente) efetivar a inclusão - da forma como isso for possível. Para além desses obstáculos, nos deparamos ainda com escolas reféns da racionalidade, nas quais o trabalho pedagógico consiste tão somente em desenvolver habilidades intelectuais. Sob esse paradigma, as emoções não encontram espaço - na verdade, deveriam efetivamente ser banidas da escola. Da mesma forma, os aspectos emocionais do professor são silenciados - e as formas como ele sente e dá sentido ao seu trabalho são descartadas, como se fosse possível separar emoção e razão. Produtos de um sistema no qual pensar é mais importante que sentir, as professoras participantes relatam dificuldades, estratégias e possibilidades, mas têm dificuldade para exprimir o que sentem.

Sob a perspectiva histórico-cultural do desenvolvimento, compreendemos que as emoções se relacionam aos significados e sentidos atribuídos à docência pelas professoras, constituindo a consciência humana. Embora não tenha chegado a sistematizar sua própria teoria acerca das emoções devido à sua morte precoce, as contribuições de Vigotski $(1997,2004,2011)$ são fundamentais ao defender a importância dos aspectos emocionais. Ao abordar uma questão frequentemente negligenciada, o autor expõe a indissociabilidade entre cognição e emoção em todos os contextos da ação humana.

As emoções humanas são processos dinâmicos em constante (re)elaboração e desenvolvimento que permitem a expressão do homem em um contexto que é determinado cultural e historicamente. Nesse sentido, constituem as funções psicológicas superiores, mediatizando a relação do homem com seu meio, permitindo que revele aspectos de seu psiquismo (como suas vontades, intenções, desejos, etc.). Ao longo do desenvolvimento, e tal como as demais funções psicológicas superiores, as emoções foram refinadas pela mediação semiótica, possível através do processo de interação social. Dessa forma, as emoções são culturalizadas, ou seja, relacionam-se a determinadas formas de compreender e vivenciar a realidade; estão, portanto, em constante modificação e desenvolvimento. Sua dinamicidade permite ao homem viver em sociedade, atuando como mediadoras e formas de expressão para as vivências internas, formas através das quais o indivíduo apreende a realidade.

As emoções reveladas pelas professoras por meio de suas fotografias desvelam possibilidades de ser e estar no contexto concreto em que se encontram, indicando caminhos possíveis para o enfrentamento da própria realidade. Dessa forma, assim como a satisfação e a alegria com o progresso dos alunos, também a tristeza, a compaixão e a frustração validam a ação real das professoras em um contexto que nem sempre produz os resultados esperados. 
Compreendemos que as emoções (conscientes ou não) das professoras Rosa, Margarida e Violeta influenciam o processo de inclusão escolar, concretizando-se na adoção de práticas que evidenciam suas heranças culturais, ideológicas e históricas. Amalgamadas a seus pensamentos e ações, as emoções configuram formas particulares de compreender a inclusão, concretizadas nas formas como cada professora acredita, deseja e conduz o processo de ensino-aprendizagem.

É preciso desenvolver um olhar mais abrangente, que perceba o professor também como pessoa, diante de suas limitações e possibilidades, inserido em uma rede maior de significados e sentidos que é a escola. Por isso, reconhecemos que o professor - responsável por promover a aprendizagem, que deve desenvolver práticas que permitam o desenvolvimento integral de todos os alunos; cujo olhar para a necessidade educacional especial deve ser sempre positivo e desafiador - também sofre.

Os sentidos atribuídos às fotografias pelas professoras Violeta, Margarida e Rosa revelam uma subjetividade conformada pelas marcas do sistema escolar do qual fazem parte, no qual a racionalidade minimiza e subjuga as emoções. No entanto, os dados indicam que, embora o sistema escolar ainda se encontre alinhado ao antigo paradigma cartesiano, conferindo à escola a primazia do cognitivo, a dimensão emocional (embora muitas vezes ignorada) está sempre presente no contexto escolar, permeando as escolhas, intenções e práticas desenvolvidas na sala de aula.

Como o discurso das professoras participantes da pesquisa aponta, o contexto escolar ainda permanece sob o domínio cartesiano da racionalidade, no qual abordar e expressar as emoções parece distanciar-se dos princípios da escola. A partir dessa constatação, e em enfrentamento a essa realidade, defendemos que a vivência das emoções precisa ser legitimada como expressão genuína e concreta dos sentidos pessoais e subjetivos atribuídos às práticas e relações estabelecidas no interior de cada escola, promovendo novas formas de conceber a aprendizagem. A vivência das próprias emoções é uma possibilidade que não pode ser negada ao professor. Emocionar-se e reconhecer suas emoções é também um direito docente, que implica em considerá-lo como ser integral que pensa, age e também sente. 


\section{REFERÊNCIAS}

AGUIAR, Wanda Maria Junqueira de. A escolha na orientação profissional: contribuições da psicologia sócio-histórica. Psic. Da Ed., São Paulo, n. 23, p. 11-25, 2006.

ARROYO, Miguel González. Ofício de mestre. 15. ed. 2. reimp. Petrópolis: Vozes, 2017.

BARDIN, Laurence. Análise de conteúdo. Tradução de Luís Antero Reto e Augusto Pinheiro. Lisboa: Edições 70, 1977.

BRASIL. Ministério da Educação. Secretaria de Educação Especial. Diretrizes nacionais para a educação especial na educação básica. Brasília: MEC; SEESP, 2001.

CAMARGO, Denise de. As emoções e a escola. Curitiba: Travessa dos Editores, 2004.

CRUZ, Roberto Moraes et al. Saúde docente, condições e carga de trabalho. REID Revista Electrónica de Investigación y Docencia, Jaén, n. 4, p. 147-160, jul. 2010.

FARIA, Paula Maria Ferreira de; CAMARGO, Denise de. As emoções do professor frente ao processo de inclusão escolar: uma revisão sistemática. Revista Brasileira de Educação Especial, Marília, v. 24, n. 2, p. 217-228, abr.-jun. 2018.

GIL, Antônio Carlos. Métodos e técnicas de pesquisa social. 6. ed. São Paulo, SP: Atlas, 2008.

GONZÁLEZ REY, Fernando Luis. Subjetividad, cultura e investigación cualitativa en psicología: La ciencia como producción culturalmente situada. Liminales: Escritos sobre Psicología e Sociedad, Santiago, v. 1, n. 4, p. 13-36, 2013.

MATTOS, Laura Kemp de; ZANELLA, Andréa Vieira; NUERNBERG, Adriano Henrique. Entre olhares e (in)visibilidades: reflexões sobre fotografia como produção dialógica. Fractal Rev. Psicol., Niterói, v. 26, n. 3, p. 901-918, 2014.

NEIVA-SILVA, Lucas; KOLLER, Sílvia Helena. O uso da fotografia na pesquisa em Psicologia. Estudos de Psicologia, Natal, v. 7, n. 2, p. 237-250, 2002.

REIS, Eduardo José Farias Borges dos et al. Docência e exaustão emocional. Educ. Soc., Campinas, v. 27, n. 94, p. 229-253, jan./abr. 2006.

SAMPAIO, Cristiane Teixeira; SAMPAIO, Sônia Maria Rocha. Educação inclusiva: o professor mediando para a vida. Salvador: EDUFBA, 2009.

SOUZA, Vera Lucia Trevisan de; PETRONI, Ana Paula; ANDRADA, Paula Costa de. A afetividade como traço da constituição identitária docente: o olhar da psicologia. Psicol. Soc., Belo Horizonte, v. 25, n. 3, p. 527-537, 2013.

TASSONI, Elvira Cristina Martins; LEITE, Sérgio Antônio da Silva. Um estudo sobre emoções e sentimentos na aprendizagem escolar. Comunicações, Piracicaba, n. 18, v. 2, p. 79-91, jul./dez. 2011. 
UNESCO (ORGANIZAÇÃO DAS NAÇÕES UNIDAS PARA A EDUCAÇÃO, CIÊNCIA E CULTURA). Declaração de Salamanca sobre principios, políticas e práticas na área das necessidades educativas especiais. Salamanca: UNESCO, 1994.

VIGOTSKI, Lev Semionovitch. Obras escogidas $V$ : fundamentos de defectología Madrid: Visor, 1997.

VIGOTSKI, Lev Semionovitch. Psicologia pedagógica. 2. ed. Tradução de Paulo Bezerra. São Paulo: Martins Fontes, 2004.

VIGOTSKI, Lev Semionovitch. A defectologia e o estudo do desenvolvimento e da educação da criança anormal. Educação e Pesquisa, São Paulo, v. 37, n. 4, p. 861-870, 2011.

Texto recebido em 26/01/2020.

Texto aprovado em 06/11/2020. 